\title{
Guiding Pediatric Patients in Dental Appointments Through Local Anesthesia Sequence
}

\author{
Nahid Ramazani (iD) ${ }^{1,}$ \\ ${ }^{1}$ Department of Pediatric Dentistry, Children and Adolescents Health Research Center, Oral and Dental Disease Research Center, Zahedan University of Medical Sciences, \\ Zahedan, Iran \\ "Corresponding author: Department of Pediatric Dentistry, Children and Adolescents Health Research Center, Oral and Dental Disease Research Center, Zahedan University of \\ Medical Sciences, Zahedan, Iran. Email: ramazani77@gmail.com
}

Received 2020 August 28; Revised 2020 November 22; Accepted 2020 November 24.

Keywords: Keywords: Child, Pediatric Dentistry, Dental Anesthesia

\section{Dear editor,}

A prerequisite to delivering routine in-office dental services is to guide pediatric patients during dental appointments (1). To achieve the best treatment outcomes, the concept of behavioral management should be considered along with proper treatment planning. Avariety of factors, such as developmental age, level of cooperation, temperament, complexity, and duration of operation, and history of dental treatment, may be influential (2-5). One of the critical factors affecting the child's behavior and cooperation during dental appointments is the previous experience of dental injections (6).

According to behavioral management techniques, pediatric dentists prefer a quadrant dental treatment plan (7). Generally, without any pain or acute infection, and different teeth having nearly the same condition, restorative care is often introduced in the upper posterior teeth. Thereafter, the lower posterior area can be restored. The reason for choosing this sequence of procedures is that buccal infiltration injections are more tolerated by children than lower block injections during anesthetic procedures (7); therefore, the child is less likely to oppose the next visit. By using communicative behavior management techniques, the majority of children are approachable for routine dental procedures in dental offices. However, adherence to the mentioned treatment sequence is not always possible, especially for three- to six-year-old children. One obvious reason is that the needle must be inserted in at least two different buccal points to achieve proper infiltration pulpal anesthesia; this experience is often perceived as unpleasant by the child (6).

Moreover, unpleasant palatal injections, which is al- most necessary, may lead to behavioral problems. Even if a less painful transpapillary palatal injection is conducted (8), the child may feel discomfort (9). In comparison with the lower block anesthesia, the practitioner may encounter the insufficiency of pulpal anesthesia in the upper posterior teeth due to some lateral innervation and decide to use supplementary injections. Also, numbness in the lower block anesthesia may be another cause of disruptive behavior (10). Overall, by increasing the number of dental sessions, the likelihood of behavioral problems increases.

In pediatric dentistry, it is important to schedule the best treatment plan to keep the child cooperative. Nevertheless, the importance of the first dental session is evident. The first treatment encounter with a pediatric patient is of great importance for not only reducing anxiety in the initial visit but also managing the patient's response to the subsequent treatment sessions. The dentist must plan to maintain the child's cooperation in the long run until all dental treatments are completed. We believe that it is not necessary to adhere to the sequence arrangement of teeth from maxillary to mandibular teeth. As stated earlier, there are numerous parameters involved. In practice, to describe the best sequence of quadrant dental treatment with respect to the child's cooperation during dental sessions, expert judgment is required. Besides providing a high-quality dental treatment through scheduling a proper treatment sequence, we can establish a trustful relationship between the practitioners, pediatric patients, and their families, address the children's fear and anxiety, and minimize the chance of their reluctance or opposition to the next dental session. 


\section{Footnotes}

Authors' Contribution: NR evaluated related articles, extracted useful content from them, and drafted the letter, revised and approved it.

Conflict of Interests: There is no conflict of interest.

Funding/Support: There is no funding.

\section{References}

1. Lee DW, Kim JG, Yang YM. The Influence of Parenting Style on Child Behavior and Dental Anxiety. Pediatr Dent. 2018;40(5):327-33. [PubMed: 30355427].

2. Wilson S. Management of child patient behavior: quality of care, fear and anxiety, and the child patient.JEndod.2013;39(3 Suppl):S73-7. doi: 10.1016/j.joen.2012.11.040. [PubMed: 23439049].

3. Jamali Z, Najafpour E, Ebrahim Adhami Z, Sighari Deljavan A, Aminabadi NA, Shirazi S. Does the length of dental procedure influence children's behavior during and after treatment? A systematic review and critical appraisal.J Dent Res Dent Clin Dent Prospects. 2018;12(1):6876. doi: 10.15171/joddd.2018.011. [PubMed: 29732024]. [PubMed Central: PMC5928478]
4. Jamali Z, Vatandoost M, Erfanparast L, Aminabadi NA, Shirazi S. The relationship between children's media habits and their anxiety and behaviour during dental treatment. Acta Odontol Scand. 2018;76(3):161-8 doi: 10.1080/00016357.2017.1396493. [PubMed: 29105531].

5. Aminabadi NA, Najafpour E, Erfanparast L, Jamali Z, Pournaghi-Azar F, Tamjid-Shabestari S, et al. Oral health status, dental anxiety, and behavior-management problems in children with oppositional defiant disorder. Eur J Oral Sci. 2016;124(1):45-51. doi: 10.1111/eos.12236. [PubMed: 26707341].

6. Ram D, Amir E, Keren R, Shapira J, Davidovich E. Mandibular block or maxillary infiltration: does it influence children's opposition to a subsequent dental visit? J Clin Pediatr Dent. 2012;36(3):245-9. [PubMed: 22838225].

7. Casamassimo PSFJH, McTigue DJ, Nowak A. Pediatric Dentistry, Infancy through Adolescence. 6th ed. Saunders: Elsevier; 2018.

8. Koch GPS, Espelid I, Haubek D. Pediatric Dentistry-A Clinical Approach. Wiley-Blackwell; 2017.

9. Kamath PS. A novel distraction technique for pain management during local anesthesia administration in pediatric patients. J Clin Pediatr Dent. 2013;38(1):45-7. doi: 10.17796/jcpd.38.1.265807t236570hx7. [PubMed: 24579282].

10. Armfield JM, Heaton LJ. Management of fear and anxiety in the dental clinic: a review. Aust Dent J. 2013;58(4):390-407. quiz 531. doi 10.1111/adj.12118. [PubMed: 24320894] 